\title{
NATURAL HISTORY OF BENIGN PROSTATIC HYPERPLASIA: APPROPRIATE CASE DEFINITION AND ESTIMATION OF ITS PREVALENCE IN THE COMMUNITY*
}

\author{
J. L. H. RUUD BOSCH, M.D., WIM C. J. HOP, WIM J. KIRKELS, M.D., Ph.D., \\ AND FRITZ H. SCHRÖDER, M.D., PH.D
}

\begin{abstract}
There is no consensus about a case definition of benign prostatic hyperplasia (BPH). In the present study, BPH prevalence rates were determined using various case definitions based on a combination of clinical parameters used to describe the properties of BPH: symptoms of prostatism, prostate volume increase, and bladder outflow obstruction. The aim of this study-in a community-based population of 502 men (55-74 years of age) without prostate cancer-was to determine the relative impact on prevalence rates of the inclusion of these different parameters (and of different cutoff values for these parameters) in a case definition of BPH. There is agreement that age is the dominant determinant of BPH. However, of 28 different case definitions that were formulated, only eight gave a statistically significant increase in the prevalence of $\mathrm{BPH}$ with age. The highest overall prevalence of $19 \%(95 \%$ confidence interval $[\mathrm{Cl}], 15-23 \%)$ occurred using the definition that combines a prostate volume $>30 \mathrm{~cm}^{3}$ and an International Prostate Symptom Score (IPSS) $>7$. The lowest prevalence rate of $4.3 \%(95 \% \mathrm{Cl}, 2-6 \%)$ occurred using the definition that combines a prostate volume $>30 \mathrm{~cm}^{3}$, an IPSS $>7$, a maximum flow rate $<10 \mathrm{~mL} / \mathrm{s}$, and the presence of a postvoid residual urine volume $>50 \mathrm{~mL}$. Thus, prevalence rates depend very much on the parameters used in a case definition. Follow-up will establish which men will eventually request a workup and treatment for $\mathrm{BPH}$ and will help determine the best clinical definition of BPH. UROLOGY` 46: 34-40, 1995.
\end{abstract}

$\mathbf{T}$ ransurethral resection of the prostate for benign prostatic hyperplasia (BPH) is one of most common surgical procedures performed in men $>65$ years of age. ${ }^{1,2}$ However, prostatectomy rates are poor indicators of the prevalence of the disease because of biases related to thresholds of referral, availability of health facilities, and differing decision algorithms among surgeons. ${ }^{1}$ The classic clinical picture of BPH has been described as a combination of three properties: an increased prostate volume, the presence of symptoms of prostatism, and evidence of bladder outflow obstruction. ${ }^{3}$ However, there is no consensus about a clinical case definition of $\mathrm{BPH}$,

\footnotetext{
*This study has been supported by a grant from the Europe Against Cancer program of the European Community and by an educational grant from SmithKline Beecham Pharmaceuticals.

From the Department of Urology, Erasmus University and Academic Hospital (J.L.H.R.B., W.J.K., F.H.S.), and Department of Epidemiology and Biostatistics, Erasmus University (W.C.J.H.), Rotterdam, The Netherlands

Requests for reprints: J.L.H. Ruud Bosch, M.D., Department of Urology, H 1073, Academisch Ziekenhuis Rotterdam-Dijkzigt, Dr. Molewaterplein 40, 3015 GD Rotterdam, The Netherlands
}

primarily because there is neither agreement about the parameters that should be used to describe the properties of $\mathrm{BPH}$, nor about the normal range of values for these parameters. There is also a lack of strong correlation between these parameters. It is, therefore, necessary to address the three properties of BPH separately before they are considered in relation to each other and before they can be used to estimate the prevalence of $\mathrm{BPH}$ in the community.

The present study attempted to define the syndrome of BPH in various ways based on relevant parameters used in daily clinical practice: the validated International Prostate Symptom Score (IPSS) ${ }^{4}$ prostate volume, and parameters used to screen for bladder outflow obstruction, i.e., urinary flow rate and postvoid residual urine volume. No preselection was made on the basis of symptoms, prostate volume, or urinary flow rate.

\section{MATERIALS AND METHODOLOGY}

\section{STUdY Design}

The community-based data on BPH presented in this article were collected as part of a randomized 
pilot study designed to evaluate the value of screening for prostate cancer. The municipal authorities of the city of Rotterdam created a database containing the addresses of all men aged $55-74$ years residing in four areas of the city. A total of 1186 men accepted the invitation to participate in the study and were stratified into four 5-year age groups between 55 and 74 years. The response rates for the four age groups varied between $33 \%$ and $36.3 \%$. This resulted in a community-based population with a slight overrepresentation of men aged 60-64 years and a slight under-representation of men aged 55-59 years (Table I).

Serum prostate-specific antigen (PSA; Hybritech assay) was used as a prescreening tool. If the PSA value was $>10 \mathrm{ng} / \mathrm{mL}$, a workup was advised because of the high probability of prostate cancer. ${ }^{5}$ of 30 men who were excluded from randomization in the study, 15 were ultimately diagnosed with prostate cancer.

The remaining 1156 men were randomly assigned to a screening or a no screening group. The 554 men assigned to the screening group were further examined by digital rectal examination (DRE) and transrectal ultrasound (TRUS) of the prostate. Prostate biopsies were taken if DRE or TRUS, or both, were abnormal. The 10 men in whom biopsies were positive for prostate cancer, the 39 who had undergone a previous operation of the lower urinary tract, and the 3 who refused the TRUS examination were excluded from the evaluation of the prevalence of BPH. Thus, a community-based population was established comprising 502 men in whom prostate cancer had been excluded with reasonable certainty and who had not previously undergone a prostate operation.

This study of the prevalence of BPH was one of several substudies planned from the screen versus no screen pilot study. The parameters studied included uroflowmetry and the determination of the postvoid residual urine volume by transabdominal ultrasound, performed in 494 and 326 consecutive men, respectively.

\section{PROCEDURES}

Symptoms: The symptom questionnaire used is the validated American Urological Association (AUA) index, ${ }^{6}$ which has been adopted by the World Health Organization as the IPSS after addition of one disease-specific quality of life question (scale 0-6). ${ }^{4}$ Based on correlations between the symptom index and other scores, three subclasses of men were created according to total score results: those with minor (IPSS 0-7), moderate (IPSS 8-19), and severe (IPSS 20-35) symptoms. ${ }^{6}$

An analysis of the symptom scores in this commu-
TABLE I. Frequency distribution of men in four age groups between 55 and 74 years of age in the general community population and in the population of study participants

\begin{tabular}{ccc}
\hline $\begin{array}{c}\text { Age } \\
(\mathbf{y r})\end{array}$ & $\begin{array}{c}\text { Community } \\
\text { Population (\%) }\end{array}$ & $\begin{array}{c}\text { Study } \\
\text { Participants (\%) }\end{array}$ \\
\hline $55-59$ & 25.8 & 20.9 \\
$60-64$ & 27.9 & 32.0 \\
$65-69$ & 25.6 & 26.1 \\
$70-74$ & 20.7 & 21.0 \\
Total & 100 & 100 \\
\hline
\end{tabular}

nity-based sample of men showed a weak correlation between age and total IPSS $(r=0.09 ; \mathrm{P}=0.04)^{7}$ Overall, $70 \%$ of the men had no or minor symptoms, $24 \%$ were moderately symptomatic, and $6 \%$ were severely symptomatic. There was only a small variation among age groups in the percentage of men with severe symptoms (range, 5.3-6.5\%).

Prostate Volume: TRUS was performed with a 7 $\mathrm{MHz}$ multiplane sector scanning probe (Bruel \& Kjaer). The planimetric technique of volume measurement was used. ${ }^{8}$ The reliability of this method has been shown in a previous study. ${ }^{9}$ Because the specific gravity of prostatic tissue is approximately $1,{ }^{10}$ the prostate volume in cubic centimeters as determined by the ultrasound method was directly compared with prostate weight in grams when comparisons were made with other studies reporting prostate weights. An analysis of prostate volume in this community-based sample of men showed a weak correlation between total prostate volume and age $(r=0.26 ; \mathrm{P}<0.001) .{ }^{11}$ Almost all men $(95 \%)$ aged $55-74$ years have a prostate volume of $>20 \mathrm{~cm}^{3}$. There is a statistically significant trend $(P<0.001)$ for an increase in the percentage of men with a volume of $>30 \mathrm{~cm}^{3}$ per 5-year age interval, as well as in the percentage of men with volumes $>40$ and $>50$ $\mathrm{cm}^{3}$.

Urodynamic Parameters: Uroflowmetry (mL/s) was done using a flowmeter (Dantec Urodyn 1000); the maximum flow rate $\left(Q_{\max }\right)$ and the accompanying voided volume were recorded. The postvoid residual urine volume (in milliliters) was measured by transabdominal ultrasound using an Aloka machine with a $3.5 \mathrm{MHz}$ hand-held probe. Volume was calculated using the formula ${ }^{12}$ :

$$
\pi / 6 \times(\text { width }) \times(\text { height }) \times(\text { depth })
$$

An analysis of the urodynamic parameters showed that of 494 consecutive men who were asked to void in the flowmeter, 62 (13\%) were unable to do so at that particular moment. ${ }^{7}$ The initial bladder volume 
was $\geq 100 \mathrm{~mL}$ in $83 \%$ of those men who voided. In the prevalence estimations of clinical $\mathrm{BPH}$, those men who could not void were categorized as having a flow rate below the chosen cutoff value (either 10 or $15 \mathrm{~mL} / \mathrm{s}$ ). On average, $76 \%$ of the men had a maximum flow rate of $<15 \mathrm{~mL} / \mathrm{s}$ and $43 \%$ had a maximum flow rate of $<10 \mathrm{~mL} / \mathrm{s}$. The correlation between maximum flow rate and age was not significant $(r=-0.08 ; \mathrm{P}=0.08)$.

No flow rates were discarded because of low volume. Thus, the flow rate data indicate the results obtained in a setting where men can be seen only once, as would be the case in population studies of the prevalence of $\mathrm{BPH}$ and related symptoms. The flow rate values would probably have been somewhat higher if repeated measurements were made in selected patients. Overall, $17 \%$ of the men in whom uroflowmetry was performed had a residual urine volume $>50 \mathrm{~mL}$. There was a statistically significant trend $(P=0.004)$ for an increase in this percentage with age, from $12 \%$ for men $55-64$ years, versus $18 \%$ for men 65-69 years, and 30\% for men $70-74$ years. Overall, the postvoid residual urine volume was poorly correlated with age $(r=0.12 ; \mathrm{P}=0.03)$.

\section{Criteria on Which Prevalence Rates Can BE BASED}

The following criteria were formulated for several case definitions of clinical $\mathrm{BPH}$, combining two or more parameters and using various "normal" (cutoff) values for these parameters:

1. The men should be at least moderately symptomatic. Men who are bothered to a greater extent, those with an IPSS >7, are more likely to benefit symptomatically from an intervention. ${ }^{6}$ Two IPSS cutoff values have been used: $>7$ (at least moderately symptomatic) or $>19$ (severely symptomatic).

2. The prostate volume as measured by TRUS should be increased. The analysis of prostate volumes in the present community population has shown that volumes measured by TRUS in living men are $21-28 \%$ larger than those measured at autopsy, and that $95 \%$ of the men $55-74$ years of age have prostate volumes of $>20 \mathrm{~cm}^{3}$. ${ }^{11}$ An overestimation of the prevalence is, therefore, likely if a volume of $20 \mathrm{~cm}^{3}$ is elected as the cutoff, a value that has been derived from a review of autopsy studies by Berry et al. ${ }^{13}$ Furthermore, there is considerable overlap in size between normal and adenomatous prostates. ${ }^{13,14}$ When estimating the prevalence of clinically significant $\mathrm{BPH}$, the prostate volume cutoff value above which there is a reasonably large chance for histopathologic BPH should ideally be known. There is no ideal cutoff value, but a volume of $30 \mathrm{~cm}^{3}$ as measured by ultrasound is a more acceptable value, since it is equivalent to the average prostate volume (and corrected autopsy volume) for men around 55 years of age. A volume of $30 \mathrm{~cm}^{3}$ at that age is associated with histopathologic BPH in about half of the cases. ${ }^{14}$ Two cutoff values have been used in this evaluation: $20 \mathrm{~cm}^{3}$ and $30 \mathrm{~cm}^{3}$.

3. Voiding dysfunction determined by objective measures should be present because most physicians expect treatment of BPH to relieve obstruction caused by the enlarged prostate. The only way to determine objectively whether men are urodynamically obstructed is by performing detrusor pressure-uroflow studies, ${ }^{15}$ which unfortunately are too invasive for use in large population studies. Therefore, the determinations of maximum flow rate and/or postvoid residual urine volume are generally used as screening tests when bladder outflow obstruction is suspected. The value of the maximum flow rate determination as a meaningful parameter in the definition of clinically relevant BPH is based on the following observations. Firstly, in patients with prostate symptoms, infravesical obstruction was present in only $7 \%$ of men with a flow rate $>15 \mathrm{~mL} / \mathrm{s}^{16}$ Secondly, a peak flow rate of $<10 \mathrm{~mL} / \mathrm{s}$ indicates bladder outflow obstruction in $88 \%$ of patients, whereas a value of $10-15 \mathrm{~mL} / \mathrm{s}$ indicates obstruction in only half of the cases. ${ }^{17}$ Thirdly, no patient with a peak flow rate within 2 standard deviations of normal (equivalent to about $10 \mathrm{~mL} / \mathrm{s}$ at a voided volume of about $100 \mathrm{~mL}$ ) required surgery during a 5-year follow-up period. ${ }^{18}$ In some of the criteria for the estimation of BPH prevalence that were formulated for this study, the maximum flow rate. cutoff values were 10 or $15 \mathrm{~mL} / \mathrm{s}$.

Birch et al. ${ }^{19}$ demonstrated that the volume of postvoid residual urine may vary considerably when serial ultrasound measurements are done on the same day, but all patients in their study had residuals on all bladder scans. It has also been shown that men with normal prostates have residual urine volumes of $<12 \mathrm{~mL} .{ }^{20}$ Bruskewitz et $a^{21}{ }^{21}$ have shown that in men with symptoms of prostatism who were selected for transurethral prostatectomy, the median residual urine volume was $55 \mathrm{~mL}$ (range, 0-900 mL) and that the median residual urine volume had fallen to $10 \mathrm{~mL}$ (range, $0-150 \mathrm{~mL}$ ) 3 months postoperatively. Therefore, the mere presence of postvoid residual urine $(>50 \mathrm{~mL})$ was considered a meaningful parameter for use in the estimation of the prevalence of BPH in the present study. ${ }^{20}$

4. The primary determinant of BPH occurrence is age. $^{22}$ It was, therefore, postulated that the increase per 5-year age group of the percentage of 
men who satisfy a certain criterion or case definition should show a statistically significant trend to be accepted as a possibly valid criterion.

\section{Statistical Analysis}

Spearman correlation coefficients ( $r$ ) were used to evaluate the relationships between age, IPSS, total prostate volume, postvoid residual urine volume, and maximum flow rate. The chi-square test for trend was used to assess whether percentages increased or decreased in relation to an ordered classification, i.e., age groups. The level of statistical significance was set at $\mathrm{P}=0.05$ (two-tailed).

\section{RESULTS}

Prevalence rates for clinical BPH were estimated, based on 28 different case definitions. These case definitions or criteria represent combinations of an increased total prostate volume $\left(>20\right.$ or $\left.>30 \mathrm{~cm}^{3}\right)$ and increased IPSS $(>7$ or $>19)$, with or without a decreased maximum flow rate $(<10 \mathrm{~mL} / \mathrm{s}$ or $<15$ $\mathrm{mL} / \mathrm{s}$ ) and with or without the presence of postvoid residual urine $(>50 \mathrm{~mL})$. These combinations were also tested with inclusion of an additional parameter, i.e., the presence of a score of $\geq 3$ on the diseasespecific quality of life question, which indicates that the men scored their feelings about their urinary condition between "about equally satisfied and dissatisfied" and "terrible."

The increase in the prevalence of clinical BPH per 5 -year age group based on the various criteria showed a statistically significant trend only for the eight criteria or case definitions summarized in Table II. Overall prevalence rates of clinical BPH for the whole population of men 55-74 years of age based on these eight different case definitions are shown in Figure 1. The highest overall prevalence (19\% [95\% $\mathrm{CI}, 15-23 \%]$ ) was found for criterion B, which represents a case definition that combines a prostate volume of $>30 \mathrm{~cm}^{3}$ and an IPSS of $>7$. The lowest prevalence rate (4.3\% [95\% CI, 2-6\%]) was found for criterion $\mathrm{H}$, which combines a prostate volume of $>30 \mathrm{~cm}^{3}$, an IPSS of $>7$, a maximum flow rate of $<10 \mathrm{~mL} / \mathrm{s}$, and the presence of a postvoid residual urine volume of $>50 \mathrm{~mL}$.

All case definitions that incorporate the presence of a postvoid residual urine volume of $>50 \mathrm{~mL}$ resulted in low overall prevalence rates.

\section{COMMENT}

Symptoms of prostatism should be present to justify a diagnosis of clinical BPH. However, the individual symptoms are not specific for BPH and are not even limited to the male population. ${ }^{23}$ The prevalence of symptoms, although interesting by itself, ${ }^{24}$ is an inappropriate indicator for the prevalence of clinical BPH. Parameters that are indicators of the other properties of BPH and of the severity of the disease, such as prostate volume, maximum flow rate, and postvoid residual urine volume, should be measured in all men without preselection and then be considered simultaneously with symptoms because there is only a poor correlation among these parameters. ${ }^{25}$

A high prevalence of $\mathrm{BPH}$ has been reported in a survey carried out in a Scottish community. ${ }^{26}$ In this survey, a complete workup, including prostate volume measurement by TRUS, was done only in selected participants (31\%) who scored above a certain cutoff value on a prostatism symptom score and/or had a urinary flow rate $<15 \mathrm{~mL} / \mathrm{s}$. The men who satisfied one of these two criteria and who were subsequently found to have a prostate volume of $>20$ $\mathrm{cm}^{3}$ were classified as having $\mathrm{BPH}$. In the present population, most men $55-74$ years of age (95\%) had a prostate volume of $>20 \mathrm{~cm}^{3} .11$ This is in agreement with the findings in the study by Garraway et al. ${ }^{26}$ which showed that $94 \%$ of the men $>60$ years had a volume of $>20 \mathrm{~cm}^{3}$. Therefore, if $20 \mathrm{~cm}^{3}$ is elected as the cutoff value above which ultrasound measured volumes are presumed to be abnormal, almost all men would exclusively and inappropriately be classified as BPH patients on the basis of symptoms if the study were designed in the aforementioned fashion. For reasons outlined in the Materials and Methodology section of this article, $30 \mathrm{~cm}^{3}$ was used as an additional cutoff value in the present evaluation.

The determinations of maximum flow rate and/or the postvoid residual urine volume are generally used as screening tests in men with suspected bladder outflow obstruction. However, maximum flow rate is a notoriously variable parameter. The fact that a man voids with a poor flow with an adequate voided volume at one point in time does not imply that flow will not be higher at another point in time. ${ }^{27}$ To qualify for the diagnosis of BPH in some of the case definitions used in our study, men were required to have sufficient symptoms and a low maximum flow rate to ensure that those men who had no symptoms and who happened to have voided poorly on one occasion were not misclassified as clinical $\mathrm{BPH}$ cases. The maximum flow rate values in our study would probably have been somewhat higher if repeated measurements were made in selected patients. This would have resulted in lower prevalence rates, if the prevalence rates had been based on a case definition of BPH that includes the parameter maximum flow rate below a certain cutoff value.

An increase in the prevalence of clinical BPH per 5-year age group based on various case definitions (criteria) showed a statistically significant trend only for the eight case definitions summarized in Table II. 
TABLE II. Percentages (95\% confidence limits) of men in age-group intervals with clinical BPH, defined according to eight criteria that showed a statistically significant trend to increase with age

\begin{tabular}{|c|c|c|c|c|c|c|c|c|c|c|}
\hline \multirow[b]{3}{*}{ Criterion } & \multirow[b]{3}{*}{ Characteristics* } & \multicolumn{8}{|c|}{ Age Group (yr) } & \multirow[b]{3}{*}{ P Value $^{t}$} \\
\hline & & \multicolumn{2}{|l|}{$55-59$} & \multicolumn{2}{|l|}{$60-64$} & \multicolumn{2}{|l|}{$65-69$} & \multicolumn{2}{|l|}{$70-74$} & \\
\hline & & $\begin{array}{c}\text { Mean } \\
(95 \% \mathrm{Cl})\end{array}$ & No. & $\begin{array}{c}\text { Mean } \\
(95 \% \mathrm{CI})\end{array}$ & No. & $\begin{array}{c}\text { Mean } \\
(95 \% \mathrm{CI})\end{array}$ & No. & $\begin{array}{c}\text { Mean } \\
(95 \% \mathrm{Cl})\end{array}$ & No. & \\
\hline $\mathrm{A}$ & $\begin{array}{l}\text { VolT }>30+\text { IPSS }>7+ \\
Q_{\max }<15\end{array}$ & $9 \%(5-16)$ & 120 & $20 \%(1-27)$ & 159 & $19 \%(13-27)$ & 132 & $27 \%(17-37)$ & 83 & 0.004 \\
\hline B & VolT $>30+$ IPSS $>7$ & $10 \%(5-17)$ & 120 & $22 \%(16-29)$ & 159 & $22 \%(15-31)$ & 132 & $28 \%(18-39)$ & 83 & 0.003 \\
\hline $\mathrm{C}$ & $\begin{array}{l}\text { VolT }>30+\text { IPSS }>7+ \\
Q_{\max }<10\end{array}$ & $6 \%(2-12)$ & 120 & $16 \%(10-22)$ & 159 & $14 \%(9-22)$ & 132 & $17 \%(10-27)$ & 83 & 0.03 \\
\hline $\mathrm{D}$ & $\begin{array}{l}\text { VolT }>30+\text { IPSS }>7+ \\
\text { QoL } \geq 3\end{array}$ & $7 \%(3-13)$ & 120 & $11 \%(6-17)$ & 159 & $10 \%(5-17)$ & 132 & $17 \%(10-27)$ & 83 & 0.04 \\
\hline $\mathrm{E}$ & $\begin{array}{l}\text { VolT }>20+\text { IPSS }>7+ \\
Q_{\max }<15+\text { PVR }>50\end{array}$ & $5 \%(1-13)$ & 76 & $2 \%(0.2-7)$ & 100 & $9 \%(4-17)$ & 90 & $13 \%(6-25)$ & 60 & 0.02 \\
\hline $\mathrm{F}$ & $\begin{array}{l}\text { VolT }>30+\text { IPSS }>7+ \\
Q_{\max }<15+\text { PVR }>50\end{array}$ & $3 \%(0.3-9)$ & 76 & $2 \%(0.2-7)$ & 100 & $7 \%(2-14)$ & 90 & $10 \%(4-21)$ & 60 & 0.02 \\
\hline G & $\begin{array}{l}\text { VolT }>30+\text { IPSS }>7+ \\
\text { PVR }>50\end{array}$ & $3 \%(0.3-9)$ & 76 & $2 \%(0.2-7)$ & 100 & $7 \%(2-14)$ & 90 & $10 \%(4-21)$ & 60 & 0.02 \\
\hline $\mathrm{H}$ & $\begin{array}{l}\text { VolT }>30+\text { IPSS }>7+ \\
Q_{\max }<10+\text { PVR }>50\end{array}$ & $1 \%(0.03-7)$ & 76 & $2 \%(0.2-7)$ & 100 & $3 \%(1-9)$ & 90 & $8 \%(3-18)$ & 60 & 0.03 \\
\hline
\end{tabular}

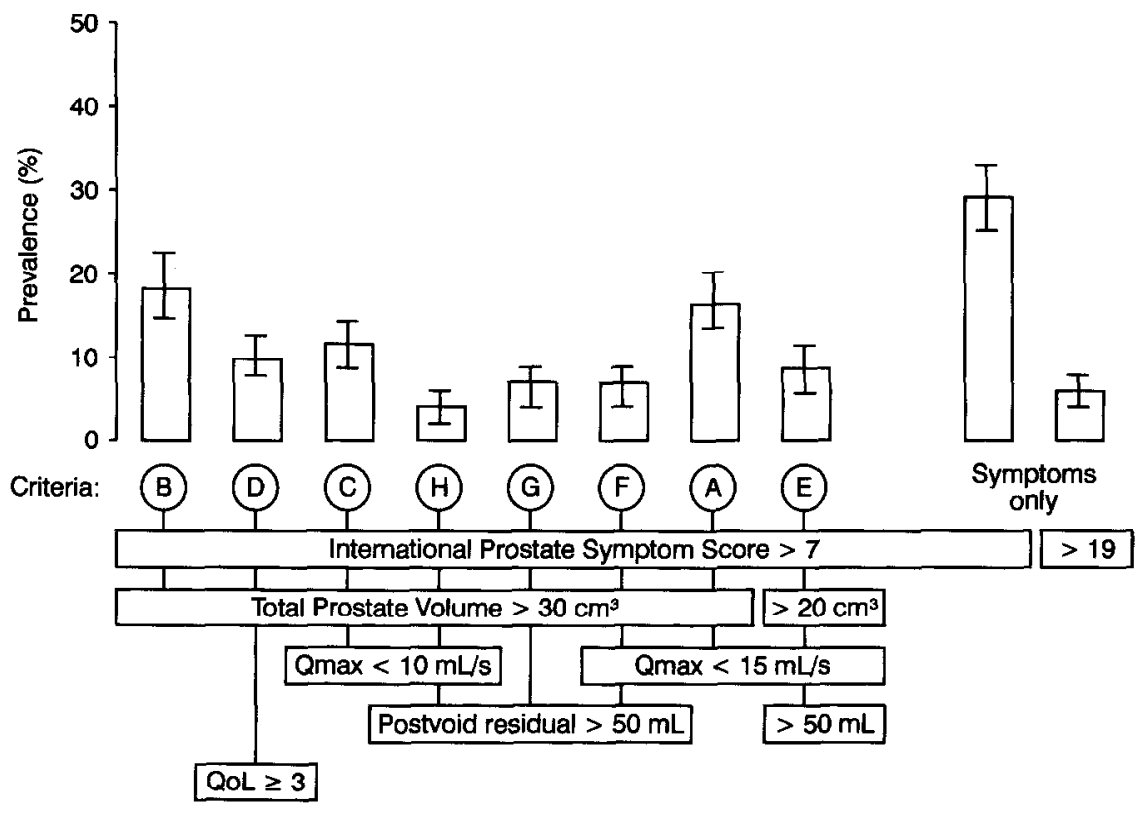

FIGURE 1. Overall prevalence rates of clinical benign prostatic hyperplasia (BPH) in a community-based population of men aged 55-74 years based on different case definitions (criteria). Straight lines connect the character for a certain criterion with the parameters and accompanying cutoff values necessary to satisfy that particular criterion. A case definition based on criterion $G$, for example, means a combination of an International Prostate Symptom Score of $>7$, a prostate volume of $>30 \mathrm{~cm}^{3}$, and postvoid residual urine volume of $>50 \mathrm{~mL}$. Error bars indicate $95 \%$ confidence intervals. $Q_{\max }=$ maximum flow rate; $\mathrm{OoL}=$ disease-specific quality of life score. 
These case definitions all resulted in prevalence rates much lower than those reported by Garraway et al. ${ }^{24}$ This is probably a result of the preselection of men in the latter study, which makes the presence of at least moderate symptoms the main determinant of the case definition in that study.

A limitation of the present study is that men 40 55 years of age were not studied. However, in the Netherlands, $96 \%$ of all patients hospitalized with the diagnosis of $\mathrm{BPH}$ are $>55$ years, ${ }^{2}$ indicating that clinical BPH is not a significant health problem in the younger age group.

The data summarized in Table II indicate additional important information. Adding maximum flow rate to the parameters of prostate volume and symptoms only slightly changes the prevalence rates if $15 \mathrm{~mL} / \mathrm{s}$ is chosen as the cutoff value (compare criteria $A$ and $B$ ), but moderately decreases the prevalence rates if $10 \mathrm{~mL} / \mathrm{s}$ is chosen as the cutoff value (compare criteria $\mathrm{C}$ and $\mathrm{B}$ ). Choosing a cutoff value of $10 \mathrm{~mL} / \mathrm{s}$ increases the likelihood that patients qualifying for that criterion are urodynamically obstructed. $^{17}$ Thus, maximum flow rate has limited impact on the BPH prevalence rates and may, therefore, be a less important parameter in the case definition of BPH. Adding the presence of postvoid residual urine to the case definition drastically reduces the prevalence rates (compare criteria $A$ and $F, B$ and $G$, and $C$ and $\mathrm{H}$ ). Although the presence of residual urine is sometimes used as a selection criterion for surgery, severe obstruction may be present without residual urine. ${ }^{28}$ Inclusion of postvoid residual urine volume may lead to a case definition that is too strict.

A decrease in prevalence rates was also observed with the addition of the quality of life score (compare criteria B and D). This parameter was added to estimate better the percentage of individuals who might benefit from an intervention, although the relationship between this score and the likelihood that a man will actually undergo a prostatectomy has yet to be established in a prospective rescreening study.

\section{CONCLUSIONS}

It is likely that a prevalence estimation based on a preselection of men by symptoms and/or flow rate or the use of a prostate volume cutoff value of $20 \mathrm{~cm}^{3}$ will overestimate the prevalence of $\mathrm{BPH}$.

The "true" prevalence of clinical BPH can presently not be determined because of a lack of consensus about a case definition for clinical BPH. This study has attempted to define clinical BPH on the basis of parameters used in daily clinical practice. Based on the approach followed, prevalence rates do not seem to be $>10 \%$ and $25-30 \%$ in the $55-59$ year and $70-$ 74 year age groups, respectively. These data are "open-ended" because detailed information on who will actually request a workup and treatment for BPH is still not available. Follow-up by rescreening will eventually provide this information and help determine the best clinical definition of BPH. It is presently unwise to accept particular rates before a clear connection has been established between these rates and the actual need for treatment.

\section{REFERENCES}

1. Barry MJ: Epidemiology and natural history of benign prostatic hyperplasia. Urol Clin North Am 17: 495-507, 1990.

2. Bosch JLHR: Epidemiologie van benigne prostaathyperplasie. Diagn Inform Med Stat 15: 4-7, 1993.

3. Hald $\mathrm{T}$ : Urodynamics in benign prostatic hyperplasia: a survey. Prostate (suppl 2): 69-77, 1989.

4. Mebust W, Roizo R, Schröder F, and Villers A: Correlations between pathology, clinical symptoms and the course of the disease, in: Cockett AT, Aso Y, Chatelain C, Denis L, Griffiths K, Khoury S, and Murphy G (Eds): Proceedings of the International Consultation on Benign Prostatic Hyperplasia. Geneva, World Health Organization, 1992, pp. 53-62.

5. Catalona WJ, Smith DS, Ratliff TL, Dodds KM, Coplen DE, Yuan JJ, Petros JA, and Andriole GL: Measurement of prostatespecific antigen in serum as a screening test for prostate cancer. N Engl J Med 324: 1156-1161, 1991.

6. Barry, MJ, Fowler FJ Jr, O'Leary MP, Bruskewitz RC, Holtgrewe HL, Mebust WK, and Cockett AT: The American Urological Association symptom index for benign prostatic hyperplasia. The Measurement Committee of the American Urological Association. J Urol 148: 1549-1557, discussion 1564, 1992.

7. Bosch JLHR, Hop WCJ, Kirkels WJ, and Schröder FH: The international prostate symptom score in a community-based sample of men between fifty-five and seventy-four years of age. Br J Urol 75: 622-630, 1995.

8. Torp-Pedersen S, Juul N, and Jakobsen $\mathrm{H}$ : Transrectal prostatic ultrasonography. Equipment, normal findings, benign hyperplasia and cancer. Scand J Urol Nephrol (suppl 107): 1925, 1988.

9. Davidson PJ, Niemer QH, and Schröder FH: Prostate volume measurement with the $7 \mathrm{MHz}$ transrectal probe. $\mathrm{Br} \mathrm{J}$ Urol 71: 73-74, 1993.

10. Abu-Yousef MM, and Narayana AS: Transabdominal ultrasound in the evaluation of prostate size. J Clin Ultrasound 10 : 275-278, 1982.

11. Bosch JLHR, Hop WCJ, Niemer AQ, Bangma $\mathrm{CH}$, Kirkels WJ, and Schröder FH: Parameters of prostate volume and shape in a community-based population of men between fifty-five and seventy-four years of age. J Urol 152: 1501-1505, 1994.

12. Roehrborn CG, and Peters PC: Can transabdominal ultrasound estimation of postvoiding residual (PVR) replace catheterization? Urology 31: 445-449, 1988.

13. Berry SJ, Coffey DS, Walsh PC, and Ewing LL: The devel opment of human benign prostatic hyperplasia with age. J Urol 132: 474-479, 1984.

14. Jakobsen H, Torp-Pedersen S, and Juul N: Ultrasonic evaluation of age-related human prostatic growth and development of benign prostatic hyperplasia. Scand J Urol Nephrol (suppl 107): 26-31, 1988.

15. Griffiths DJ: Urodynamic assessment of bladder function. Br J Urol 49: 29-36, 1977.

16. Gerstenberg TC, Andersen JT, Klarskov P, Ramirez D, 
and Hald T: High flow infravesical obstruction in men: symptomatology, urodynamics and the results of surgery. J Urol 127: 943-945, 1982.

17. Hald T, Nielsen KK, and Nordling J: Clinical urodynamics in benign prostatic hyperplasia. Eur Urol Update Series 2 : 74-79, 1993.

18. Ball AJ, Feneley RC, and Abrams PH: The natural history of untreated "prostatism." Br J Urol 53: 613-616, 1981.

19. Birch NC, Hurst G, and Doyle PT: Serial residual volumes in men with prostatic hypertrophy. $\mathrm{Br} \mathrm{J}$ Urol 62: 571-575, 1988.

20. Hinman F Jr, and Cox CE: Residual urine volumes in normal male subjects. J Urol 97: 641-645, 1967.

21. Bruskewitz RC, Iversen $P$, and Madsen PO: Value of postvoid residual urine determination in evaluation of prostatism. Urology 20: 602-604, 1982.

22. Barry MJ: Epidemiology and natural history of benign prostatic hyperplasia, in: Lepor $\mathrm{H}$, and Lawson RK (Eds): Prostate Diseases. Philadelphia, W.B. Saunders, 1993, pp. 96-107.

23. Lepor $\mathrm{H}$, and Machi $\mathrm{G}$ : Comparison of AUA symptom index in unselected males and females between fifty-five and seventy-nine years of age. Urology 42: 36-40, 1993.

24. Chute CG, Panser LA, Girman CJ, Oesterling JF, Guess $\mathrm{HA}$, Jacobsen SJ, and Lieber MM: The prevalence of prostatism: A population-based survey of urinary symptoms. J Urol 150 : 85-89, 1993.

25. Barry MJ, Cockett ATK, Holtgrewe HL, McConnell JD, Sihelnik SA, and Winfield HN: Relationship of symptoms of prostatism to commonly used physiological and anatomical measures of the severity of benign prostatic hyperplasia. J Urol 150: 351-358, 1993.

26. Garraway WM, Collins GN, and Lee RJ: High prevalence of henign prostatic hypertrophy in the community. Lancet 338 : 469-471, 1991.

27. Golomb J, Lindner A, Siegel Y, and Korczak D: Variability and circadian changes in home uroflowmetry in patients with benign prostatic hyperplasia compared to normal controls. J Urol 147: 1044-1047, 1992.

28. Christensen MM, and Bruskewitz RC: Clinical manifestations of benign prostatic hyperplasia and indications for therapeutic intervention. Urol Clin North Am 17: 509-516, 1990. 